\title{
SVN \\ Adenosine to facilitate the clipping of cerebral aneurysms: literature review
}

\author{
Virendra R Desai, ${ }^{1}$ Alejandro L Rosas, ${ }^{2}$ Gavin W Britz ${ }^{1}$
}

To cite: Desai VR, Rosas AL, Britz GW. Adenosine to facilitate the clipping of cerebral aneurysms: literature review. Stroke and Vascular Neurology 2017;0: e000082. doi:10.1136/ svn-2017-000082

- Additional material is published online only. To view please visit the journal online (http://dx.doi.org/10.1136/10. 1136/svn-2017-000082)

Received 7 March 2017 Revised 10 May 2017 Accepted 11 May 2017

\section{CrossMark}

${ }^{1}$ Department of Neurosurgery, Houston Methodist Neurological Institute, Houston Methodist Hospital, Houston, Texas, USA ${ }^{2}$ Department of Anesthesiology and Critical Care, Houston Methodist Hospital, Houston, Texas, USA

Correspondence to Dr Gavin W Britz; gbritz@houstonmethodist.org

\section{ABSTRACT}

Cerebral aneurysms have a high mortality rate when ruptured. Endovascular techniques have improved substantially in treating this pathology. However, surgical clip ligation remains the preferred option for some aneurysms. Various techniques are used intraoperatively to assist the surgeon in dissecting the aneurysmal dome free of surrounding tissue and placing a clip around the neck safely and effectively so that no nearby perforating vessels are affected and no residual remains. These techniques include temporary clip ligation, endovascular balloon occlusion and cardiac standstill. Adenosine use is one viable option for induced cardiac arrest leading to a short period of controlled hypotension. Its predictable course of action, rapid onset and offset and rare incidence of adverse side effects make it an attractive agent in this regard. Below, we provide an introduction to adenosine use, describing its pharmacokinetic properties, indications, contraindications, complications and future directions.

\section{INTRODUCTION}

Aneurysmal subarachnoid haemorrhage has a high mortality rate $(40 \%-50 \%)$, and thus, prompt recognition of and proper management of aneurysms, both ruptured and unruptured, is warranted. ${ }^{1}$ With advancements in endovascular technique, the majority of intracerebral aneurysms are treated in this manner. However, some aneurysms, based on their location and/or morphology, still require surgical clip ligation. However, some aneurysms, based on their location and/or morphology, still require surgical clip ligation.

Several techniques are available to assist the surgeon in dissecting the aneurysm free of surrounding tissue, improving visualisation of the aneurysm's neck and placing a permanent clip to completely obliterate it while maintaining patency of surrounding perforating vessels. $^{2}$ Such techniques include temporary clip ligation of the proximal blood vessel, temporary cross-clamping of the extracranial carotid artery in the neck, endovascular balloon occlusion with suction, extracranial-to-intracranial bypass and cardiac standstill. $^{2-4}$ Cardiac standstill allows controlled hypotension, which can be used to reduce aneurysmal wall tension, decrease the risk of rupture and facilitate successful clip ligation and is also used to decrease bleeding. ${ }^{5}$ Current methods for cardiac standstill include non-pharmacological methods such as deep hypothermic circulatory arrest on cardiopulmonary bypass and rapid ventricular pacing, as well as pharmacological methods, with the administration of sodium nitroprusside (NP), nitroglycerin or adenosine. ${ }^{67}$

However, many of these methods have numerous drawbacks. Endovascular techniques can cause dissection or distal arterial embolic occlusion. ${ }^{34}$ Cardiopulmonary bypass has risks of arterial injury at the site of cannulation, embolic occlusion related to an aortic plaque or postoperative intracranial haemorrhage, since it requires anticoagulation. ${ }^{34}$ Temporary clip ligation of a proximal vessel has risks of stroke, dissection or rupture and also decreases visualisation. ${ }^{2} 38$ In instances where temporary arterial occlusion is difficult for anatomical reasons or impractical, adenosine use can be beneficial. ${ }^{4}$ Sodium NP and nitroglycerin have a number of side effects, including cyanide toxicity, tachyphylaxis, rebound hypertension, increased intracranial pressure and methemoglobinemia. ${ }^{59}$ In addition, nitroglycerin has a slow onset and unpredictable action. ${ }^{5}$ Ideal criteria for flow arrest in vascular surgery include the following:

- Predictable effects (especially degree and duration of hypotension)

- Few pharmacological side effects

- Titratability

- Technical feasibility and simplicity

- Low risk for procedure-related complications $^{10}$

In this review article, we provide background on adenosine use in intracranial aneurysm surgery.

\section{ADENOSINE PHARMACOKINETICS}

Adenosine is a nucleoside analogue that binds to cardiac A1 receptors, which are membrane G-protein-coupled receptors. This initiates a cascade through activation of adenylyl cyclase, decreasing intracellular cyclic AMP, 
which results in decreased inward calcium conductance. ${ }^{11}{ }^{12}$ This leads to multiple cardiac effects, including depressed sinoatrial (SA) node activity (negative chronotropic effect), slowed atrioventricular (AV) nodal conduction (negative dromotropic effect) and decreased atrial contractility and ventricular automaticity. ${ }^{12} 13$

The clinical effect is seen 10-20s after bolus injection of adenosine, leading to AV nodal blockade, bradycardia, sinus pauses and cardiac arrest, all of which manifest as a profound decrease in cardiac output and mean arterial pressure (MAP). ${ }^{411}$ Adenosine is rapidly cleared from blood by uptake into erythrocytes and vascular endothelial cells, having a short half-life of 0.6-20 s. ${ }^{5}{ }^{10} 11$ Owall et al used adenosine by continuous infusion to a mean of 29 min of controlled hypotension, with mean arterial blood pressure restored to preadenosine levels $0.5-3 \mathrm{~min}$ after discontinuation, except in two cases with cardiac arrhythmia. ${ }^{14}$ Because of its rapid onset and offset, a bolus of adenosine can allow a transient asystole with temporary hypotension that decompresses the aneurysm sac and improves visualisation without the negative effects of prolonged hypotension. ${ }^{2}$

Adenosine also acts on coronary vasculature via opening of potassium channels. This leads to hyperpolarisation of vascular smooth muscle cells, causing arterial vasodilatation. This can produce a coronary steal phenomenon so that underperfused areas, where coronary arteries are already maximally dilated, may become ischaemic. This principle underlies its use in cardiac stress testing, and it also underscores the importance of close cardiac monitoring when used in aneurysm surgery. ${ }^{3} 12$

Lastly, adenosine acts on $\mathrm{A}_{2 \beta}$-adenosine receptors on bronchial smooth muscle to cause contraction. Thus, it may induce bronchospasm, although this has only occurred in several case reports in patients with asthma or chronic obstructive pulmonary disease (COPD) ${ }^{15}$

\section{PAST USE IN CEREBROVASCULAR SURGERY}

In 1984, Sollevi et al studied 10 patients undergoing aneurysm surgery. An adenosine infusion of $0.14 \mathrm{mg}$ / $\mathrm{kg} / \mathrm{min}$ lead to a decrease in MAP by $43 \%$ (82 to $46 \mathrm{~mm}$ $\mathrm{Hg}$ ) and a mean hypotensive period of $32 \mathrm{~min}$, without signs of tachyphylaxis. They pretreated with dipyridamole (adenosine uptake inhibitor) to reduce the dose of adenosine required $(50 \%$ more adenosine required without pretreatment). ${ }^{514}$ Pulmonary vascular resistance, central venous pressure, arterial lactate and partial pressure of oxygen in arterial blood were unchanged. Whole body oxygen consumption decreased by $13 \% .^{5}$

In 1987, Owall et al studied 47 patients (46 undergoing aneurysmal clip ligation and 1 arteriovenous malformation (AVM) resection). Adenosine was infused, starting at $0.04 \mathrm{mg} / \mathrm{kg} / \mathrm{min}$ and increasing by 0.04 every $30 \mathrm{~s}$ until a desired MAP of 40-50 mm Hg was reached (range: 0.088$0.530 \mathrm{mg} / \mathrm{kg} / \mathrm{min}$ ). The hypotensive period lasted $29 \mathrm{~min}$ on average. There were no changes in pulmonary arterial pressure, pulmonary capillary wedge pressure, $\mathrm{pH}$, base excess or partial pressure of carbon dioxide in arterial blood, and no reflex tachycardia or rebound hypertension was seen. ${ }^{14}$

While Sollevi et al and Owall et al used adenosine infusions, ${ }^{5}{ }^{14}$ more recently adenosine boluses have been implemented for cardiac arrest. In 1999, Groff et al reported the first use of adenosine bolus to clip an unruptured basilar tip aneurysm in one patient. In this study, the authors used concomitant infusion of sodium $\mathrm{NP}$ and gave three doses of adenosine: $6 \mathrm{mg}$, then $12 \mathrm{mg}$ and then another $12 \mathrm{mg}$, which caused 8-13 s of profound hypotension (MAP $\sim 15 \mathrm{~mm} \mathrm{Hg}$ ) and allowed the safe and successful placement of a clip. ${ }^{8}$ In 2010, Powers et al used adenosine by bolus for clipping anterior circulation aneurysms in six patients, administering escalating doses until $30 \mathrm{~s}$ of asystole was achieved $(6 \mathrm{mg}, 12 \mathrm{mg}, 18 \mathrm{mg}$, $24 \mathrm{mg}$ and $36 \mathrm{mg}$ ). They found a rate of $1 \mathrm{mg}$ adenosine resulting in $1 \mathrm{~s}$ of asystole on average. ${ }^{11}$

However, there are no specific guidelines on bolus dosing. Two main studies address this question. ${ }^{4} 10$ Hashimoto et al used adenosine dosing in endovascular glue embolisation of AVMs with five patients (four adults and one child). The initial adenosine dose was $0.25-0.35 \mathrm{mg} / \mathrm{kg}$, with escalation by $10-20 \mathrm{mg}$ per injection, till 20-30s of MAP at 25-30 mm $\mathrm{Hg}$ was achieved, with 3-10 min between each injection. The authors also gave sodium NP, lowering MAP by $10 \%$ from baseline, to reduce postadenosine rebound hypertension. They created a scatter plot with weight-based dosing on the $\mathrm{x}$-axis $(\mathrm{mg} / \mathrm{kg})$ and several variables on the y-axis: duration of asystole, duration of MAP $<50$, duration of MAP $<30$ and MAP for first $20 \mathrm{~s}$. All of these variables had a linear relation. In other words, both the duration of asystole and a MAP $<30-50$ is linearly correlated with adenosine dose. ${ }^{1016}$ Their model shows $0.88 \mathrm{mg} / \mathrm{kg}$ is needed for $45 \mathrm{~s}$ of moderate hypotension $(\mathrm{MAP}<50)$ and $2.15 \mathrm{mg} / \mathrm{kg}$ for profound hypotension $(\mathrm{MAP}<30){ }^{10}$

Hoping to demonstrate the dose-response curve for adenosine during cerebral aneurysm clipping, Bebawy et al retrospectively reviewed 24 patients who had adenosine administration during aneurysmal clip ligation, with two-thirds unruptured and one-third ruptured and two-thirds located in the anterior circulation and one-third posterior. ${ }^{4}$ Based on their results, the authors recommend dosing at $0.3-0.4 \mathrm{mg} / \mathrm{kg}$ of ideal body weight (IBW) for $45 \mathrm{~s}$ of profound controlled hypotension, systolic blood pressure $<60$, when used in combination with a low dose volatile anaesthetic, remifentanil infusion and propofol-induced burst suppression. ${ }^{4}$ They used IBW, instead of actual body weight, because the volume of distribution of adenosine (ie, the blood volume between the intravenous injection site and the right atrium and ventricle) is unlikely to change with obesity. ${ }^{4}$ Unlike the study by Hashimoto et al above, Bebawy et al needed $1 / 5$ to $1 / 7$ the dose of adenosine primarily because of remifentanil usage, which depresses SA node activation and AV node conduction, whereas the sodium NP Hashimoto et al used can increase electrical conduction through these nodes. ${ }^{410}$ 
Bendok et al report a retrospective review of 40 patients undergoing aneurysmal clipping with adenosine use, both anterior and posterior circulations, 10 ruptured and 30 unruptured. These authors used bolus dosing of $0.3-0.4 \mathrm{mg} / \mathrm{kg}$ as in Bebawy et al with successful clip ligation in $35 / 40$ patients $(87.5 \%){ }^{17}$

Guinn et al retrospectively studied 27 patients with primarily anterior circulation aneurysms. Based on their results, the authors recommend dosing $0.24-0.42 \mathrm{mg} / \mathrm{kg}$ to get $30-60 \mathrm{~s}$ of hypotension and bradycardia. ${ }^{2}{ }^{15}$ They suggest that hypotension rather than asystole is the single most important factor in adenosine success. ${ }^{27}$

Andrade-Barazarte et al retrospectively reviewed eight patients who received adenosine during aneurysm surgery in a contralateral approach to ophthalmic segment internal carotid artery aneurysms. All were unruptured, small and saccular. The median dose of adenosine was $22.5 \mathrm{mg}$ (range $5-50 \mathrm{mg}$ ) for $20-40 \mathrm{~s}$ of asystole. ${ }^{18}$

Significant interpatient variability exists in response to adenosine and duration of asystole, and thus, the ideal dose for a certain patient is unknown until multiple test doses are given. ${ }^{12} 1619$ However, multiple test dosing with repeated cardiac arrest periods may cause cardiac or end-organ ischaemia and are impractical, or even impossible, when emergent or unexpected complications arise, such as intraoperative rupture. ${ }^{46}$ Lee $e t$ al, however, compared a multiple, escalating dose regimen with a predetermined dose regimen, based on $0.3-0.4 \mathrm{mg} / \mathrm{kg}$ and found essentially equivalent safety profiles between the two, with no cardiac complications other than two self-limited, short-lasting atrial fibrillation events in the predetermined dose group. ${ }^{16}$

Adenosine was used after intraoperative rupture to prevent devastating bleeding in 16 patients, allowing successful clip ligation with no adverse consequences in all cases. ${ }^{20}$ Powers et al also report a case in which intraoperative rupture occurred and adenosine was used to decrease bleeding, improve visualisation and eventually perform a bypass with external carotid artery to the second segment of the middle cerebral artery with saphenous vein graft. ${ }^{11}$ Vealey et al administered six large doses in succession over a 12 min time period to achieve control of a left middle cerebral artery aneurysm that had ruptured. ${ }^{21}$ Rapid ventricular pacing has a more predictable response time, and thus can be used in times of unanticipated complications, but is more invasive and complex from an anaesthesia standpoint. ${ }^{6}$

\section{INDICATIONS/STRENGTHS}

As noted above, adenosine use can induce temporary asystole and hypotension to decompress the aneurysmal dome, except when the aneurysm is calcified or fibrotic, allowing the surgeon to dissect the aneurysmal plane. ${ }^{21115}$ Currently, no specific indications for adenosine use exist, but several authors have provided expert opinion on appropriate instances for its usage (table 1).

While temporary clipping is a valuable tool, it cannot be applied in all cases. This is especially true for large or deep aneurysms in narrow corridors or near the skull base where temporary clip ligation can further obscure a limited view or is even entirely impossible. ${ }^{23} 7111517 \mathrm{In}$ these situations, adenosine-induced cardiac arrest relaxes the brain and may improve visualisation in narrow corridors. ${ }^{22}$ Moreover, temporary clip ligation only decreases blood flow from one direction, while adenosine-induced hypotension is more global and, in certain instances, can more effectively decompress the aneurysmal dome. ${ }^{23}$

Intraoperative aneurysmal rupture significantly increases morbidity and mortality, likely secondary to the bleeding itself or the ineffective or dangerous tactics employed by the surgeon. ${ }^{24}$ In this scenario, while temporary clipping is considered the gold standard, adenosine can be used as an effective synergistic tool. ${ }^{717}$ In fact, Wright et alstate that intraoperative rupture is the "clearest indication for adenosine', especially when rupture occurs early in the dissection, before proximal and distal control have been achieved. ${ }^{7}$ Nussbaum et al report one case

Table 1

\begin{tabular}{|c|c|c|}
\hline Indications & Contraindications* & $\begin{array}{l}\text { Absolute vs relative } \\
\text { contraindication }\end{array}$ \\
\hline $\begin{array}{l}\text { Large and/or deep aneurysms in narrow } \\
\text { corridors where temporary clip ligation is difficult } \\
\text { or not possible }\end{array}$ & Severe reactive airway disease & Absolute \\
\hline $\begin{array}{l}\text { In synergy with temporary clipping, especially } \\
\text { during intraoperative aneurysmal rupture }\end{array}$ & Severe coronary artery disease & Absolute \\
\hline \multirow{2}{*}{$\begin{array}{l}\text { To improve visualisation of adjacent perforating } \\
\text { arteries }\end{array}$} & Allergy & Relative \\
\hline & $\begin{array}{l}\text { Dipyridamole, methylxanthines and nimodipine inhibit } \\
\text { adenosine breakdown and uptake and can increase } \\
\text { levels }\end{array}$ & Relative \\
\hline
\end{tabular}

${ }^{*}$ Mostly provided as expert opinion by Khan et al. ${ }^{15}$ 
where temporary clipping was insufficient after intraoperative aneurysmal rupture; however, after adenosine usage, a clip was applied successfully. In their case, an anterior communicating artery aneurysm was associated with a right parietal AVM. Intraoperative rupture caused bleeding that could not be controlled with temporary clipping of the first segment of the anterior cerebral artery (A1) segment of the anterior cerebral artery. Thus, $12 \mathrm{mg}$ of adenosine was given, which caused $25 \mathrm{~s}$ of asystole, allowing visualisation and then successful clip ligation. ${ }^{24}$ Deb et al report two cases of adenosine use during intraoperative rupture.$^{25}$ One patient received $18 \mathrm{mg}(0.3 \mathrm{mg} /$ $\mathrm{kg}$ ) intravenously in conjunction with temporary clipping after aneurysmal rupture, resulting in $20 \mathrm{~s}$ of asystole and allowing successful clip ligation with no long-term consequences. ${ }^{25}$ The second patient received two $18 \mathrm{mg}$ bolus doses of adenosine with $25 \mathrm{~s}$ of asystole initially and then $15 \mathrm{~s}$, allowing successful clip ligation, although cardiac arrest requiring electrical resuscitation occurred and the patient suffered lower cranial nerve palsies, necessitating tracheostomy and prolonged hospitalisation. ${ }^{25}$ This patient however had a history of interstitial lung disease, increasing her risk of complication with adenosine use, as well as $1.5 \mathrm{~L}$ of blood loss after aneurysmal rupture and between the sequential adenosine doses. ${ }^{25}$

Adenosine can also be used in cases where temporary clip ligation fails. ${ }^{22}$ Heppner et al report a case of a basilar tip aneurysm that could not be clipped with temporary clipping of the proximal basilar artery. While temporary clipping allowed further dissection of the aneurysmal dome, the authors could not visualise all the perforators extending from the aneurysm, and thus, clipping at this point was determined unsafe. They proceeded to administer escalating doses of adenosine, up to multiple $36 \mathrm{mg}$ doses, which allowed enough visualisation to dissect the posterior perforators free from the aneurysm and successfully clip the aneurysm. ${ }^{22}$

\section{CONTRAINDICATIONS}

Overall, adenosine via bolus or by infusion is safe to use because of very limited side effects that are rapidly reversible with termination of administration, and it can be easily titrated to a desired effect. ${ }^{726}$ Nevertheless, some contraindications exist (table 1).

Adenosine can cause myocardial ischaemia in patients with coronary artery disease; it vasodilates healthy coronary arteries but not diseased ones, because they are already maximally dilated. This can cause a coronary steal phenomenon shunting blood away from diseased, underperfused areas to non-ischaemic areas. This principle underlies adenosine usage in cardiac stress testing. Multiple authors caution its use in patients with a preoperative history of myocardial infarction (MI) and recommend avoiding it in patients with severe left main coronary artery stenosis $(80 \%)$ or severe multivessel coronary artery disease (three vessels or grafts with $80 \%$ stenosis). ${ }^{3412141523}$
Adenosine-induced AV block is due to a direct adenosine effect rather than a manifestation of ischaemia, and this fact underlies its clinical use in stopping supraventricular tachycardia. ${ }^{1526}$ The Adenoscan Multicenter Trial Registry was a prospective phase III trial using fixed dose, continuous infusion adenosine in patients referred for clinically indicated cardiac perfusion imaging who were unable to perform exercise stress testing. A dosage of $0.14 \mathrm{mg} / \mathrm{kg} / \mathrm{min}$ of adenosine was infused for $6 \mathrm{~min}$ but terminated early if the patient developed significant side effects. In 9256 patients, 12 had bronchospasm (0.13\%), 1 had an MI $(0.01 \%)$ and 1 developed pulmonary oedema $(0.01 \%)$. Only $4.7 \%$ of the total adverse events were classified as severe by the investigators. ${ }^{12}{ }^{15} 26$ While $7.6 \%$ of patients (706 out of 9256) developed transient atrioventricular conduction block, the authors note that there was no difference in occurrence of ischaemia between those with versus without $\mathrm{AV}$ block.

Adenosine-induced sustained AV blockade is a rare side effect. Makaryus et al report one patient who developed sustained AV blockade after adenosine cardiac stress testing with adenosine infusing at $0.14 \mathrm{mg} / \mathrm{kg} / \mathrm{min}$ for $5 \mathrm{~min}$ and required postprocedure permanent pacemaker implantation. ${ }^{12}$ This patient had no evidence of AV node blockade on prestress test ECG, and thus the authors state that although this side effect is rare, it is possible, especially in patients with pre-existing structural heart disease. $^{12}$

Zall $e t$ al advise against adenosine use in patients with impaired renal function, secondary to its profound decrease in renal blood flow and glomerular filtration rate. This effect is temporary, not associated with renin release and rapidly reverses with discontinuation of adenosine. ${ }^{9}$ Neither rebound hypertension nor tachyphylaxis has been shown to occur after adenosine, likely because it does not activate renin-angiotensin system. ${ }^{4} 1527$

Many patients presenting with aneurysmal subarachnoid haemorrhage are medicated with nimodipine for vasospasm prophylaxis. However, as noted above, nimodipine can inhibit adenosine breakdown and uptake, and thus, care must be exercised when using adenosine during clipping of a ruptured aneurysm that is being treated with nimodipine. ${ }^{24}$ In fact, Groff et al recorded electroencephalography (EEG) and somatosensory evoked potentials (SSEPs) during adenosine use in one patient and found decreased EEG activity secondary to ischaemia but no change in SSEPs. Thus, they recommend avoiding adenosine use in patients with subarachnoid haemorrhage who may be more sensitive to ischaemia from vasospasm. ${ }^{8}$ Other authors believe adenosine can be used safely in preoperatively or intraoperatively ruptured aneurysms in patients with no pre-existing cardiac abnormalities. ${ }^{720}$

Because of adenosine's actions on bronchial smooth muscle, it may cause bronchoconstriction and thus, may be contraindicated in patients with asthma or COPD. ${ }^{1523}$

As noted above, exogenous adenosine is mostly eliminated by cellular uptake into vascular endothelium 
and erythrocytes. But it can also be metabolised to uric acid and increase uric acid levels by $15 \%$. Although this increase has been non-pathological to date, adenosine should be used cautiously in those with gout or purine metabolism defects. ${ }^{1423}$

Cerqueira et al identified risk factors for any adenosine side effect, including flushing, dyspnoea, chest pain, headache to ECG changes such AV block, ST changes and more. Female gender OR was 1.78 , body weight above median OR 1.47 and patients younger than median age OR 1.52. The authors note that these ORs are low and do not allow for clinical prediction of an adverse event in a particular patient. ${ }^{26}$

\section{COMPLICATIONS}

While adenosine use has been shown to be relatively safe with no complications in multiple studies, other studies have had rare complications. ${ }^{11} 1826$

Transient cardiac arrhythmias are occasionally seen, more commonly in those with a preoperative history of MI. ${ }^{14}$ These are typically clinically insignificant with spontaneous recovery and with no long-term sequelae. ${ }^{41617}$

Rarely, elevated troponins can occur. Bendok et al had two such patients but neither developed acute changes on ECG or echocardiogram. ${ }^{17}$ Bebawy et al also had two patients who developed transient, asymptomatic troponin increases postoperatively but had no symptoms and no cardiac dysfunction on transthoracic echocardiogram. ${ }^{4}$ Based on these results, they recommend placement of external defibrillator pads on all patients who may receive adenosine as well as postoperative troponin monitoring. ${ }^{48}$

Khan et al retrospectively reviewed 64 cases of adenosine use during aneurysmal surgery compared with 262 cases where adenosine was not used to determine perioperative cardiac complications and 30-day mortality. The authors dosed adenosine in increments of $6-12 \mathrm{mg}$ boluses to achieve $30 \mathrm{~s}$ of cardiac arrest. This dose was repeated at the request of the surgeon. The primary outcome was a composite of mortality within 30 days or a perioperative adverse cardiac event such as an MI or arrhythmia. After adjusting for incidence of coronary artery disease, the odds of reaching the primary outcome was the same between both groups, and there were no differences in length of hospital or intensive care unit stay. ${ }^{3}$

Adenosine use in cases other than cerebral aneurysm surgery has also shown limited and transient adverse consequences. Kahn et al report a case series on endovascular aortic aneurysm repair using an initial dose of $24 \mathrm{mg}$ that was escalated until $10 \mathrm{~s}$ of asystole occurred. They observed a 9\% incidence of mild cardiac complication: 2\% incidence of self-limited ST depression, 2\% atrial fibrillation requiring cardioversion, $1 \%$ transient left bundle branch block lasting $<10$ s and $4 \%$ temporary heart block requiring pacing for $<30 \mathrm{~s}$. They had no cases of bronchospasm or worsening obstructive pulmonary disease. $^{28}$
In 2014, Deb et al reported a case in which intraoperative aneurysmal rupture led to $1.5 \mathrm{~L}$ of blood loss; to reduce blood loss, two sequential adenosine boluses were administered, which lead to cardiac arrest and required electrical cardioversion. ${ }^{25}$ She awoke with lower cranial nerve palsy, resulting in tracheostomy and prolonged hospitalisation. This patient had a history of interstitial lung disease, suggesting that patients with these comorbidities may be at higher risk for an adverse cardiac event resulting from adenosine use after intraoperative aneurysmal rupture. ${ }^{25}$

In another case of intraoperative rupture with $500 \mathrm{~mL}$ of blood loss and hypotension, rapid redosing of adenosine, before full recovery of cardiac function, prolonged the hypotensive period and required chest compressions. ${ }^{2}$ Thus, prior to repeat dosing, it is important to have proper return of cardiac function. ${ }^{23} 715$ Otherwise, a carry-over effect or tachyphylaxis may be seen, although it has not been reported in the literature as of yet during cerebral aneurysm surgery. ${ }^{10} 14$

Given the possibility of transient or prolonged duration of hypotension, concern for neurological ischaemic complications exists. Bebawy et al investigated the neurological safety profile of adenosine, comparing the incidence of neurological complications with and without adenosine use. ${ }^{29}$ Although there is no mention of dosage amount or regimen, their results show that adenosine use was not associated with an increased neurological complication rate, defined as modified Rankin score $>2$ at 48 hours postoperatively or at the time of discharge. ${ }^{29}$

\section{CONCLUSIONS AND FUTURE DIRECTIONS}

Adenosine has been used successfully for ruptured and unruptured aneurysms in anterior and posterior circulations with a rare incidence of clinically significant side effects. Its rapid onset and offset and predictable action make it a valuable tool in cerebrovascular surgery. Most evidence to date has been in the form of cases series or retrospective reviews (see online supplementary table 1), signifying the need for a prospective, randomised trial of adenosine usage.

Contributors VRD, ALR and GWB contributed significantly to this work, including the concept and design of the project and the drafting, revising and final approval. All authors agree to be accountable for all aspects of the work in ensuring that questions related to the accuracy or integrity of any part of the work are appropriately investigated and resolved.

Disclaimer The views expressed within this article are those of the authors alone and not an official position of the institution Houston Methodist Hospital.

Competing interests None declared.

Provenance and peer review Not commissioned; externally peer reviewed.

Open Access This is an Open Access article distributed in accordance with the Creative Commons Attribution Non Commercial (CC BY-NC 4.0) license, which permits others to distribute, remix, adapt, build upon this work non-commercially, and license their derivative works on different terms, provided the original work is properly cited and the use is non-commercial. See: http://creativecommons.org/ licenses/by-nc/4.0/ 
(c) Article author(s) (or their employer(s) unless otherwise stated in the text of the article) 2017. All rights reserved. No commercial use is permitted unless otherwise expressly granted.

\section{REFERENCES}

1. Juvela S, Porras M, Poussa K. Natural history of unruptured intracranial aneurysms: probability of and risk factors for aneurysm rupture. J Neurosurg 2000;93:379-87.

2. Guinn NR, McDonagh DL, Borel CO, et al. Adenosine-induced transient asystole for intracranial aneurysm surgery: a retrospective review. J Neurosurg Anesthesiol 2011;23:35-40.

3. Khan SA, McDonagh DL, Adogwa O, et al. Perioperative cardiac complications and 30-day mortality in patients undergoing intracranial aneurysmal surgery with adenosine-induced flow arrest: a retrospective comparative study. Neurosurgery 2014;74:267-72.

4. Bebawy JF, Gupta DK, Bendok BR, et al. Adenosine-induced flow arrest to facilitate intracranial aneurysm clip ligation: dose-response data and safety profile. Anesth Analg 2010;110:1406-11.

5. Sollevi A, Lagerkranser $M$, Irestedt $L$, et al. Controlled hypotension with adenosine in cerebral aneurysm surgery. Anesthesiology 1984;61:400-5

6. Rangel-Castilla L, Russin JJ, Britz GW, et al. Update on transient cardiac standstill in cerebrovascular surgery. Neurosurg Rev 2015;38:595-602.

7. Wright JM, Huang CL, Sharma R, et al. Cardiac standstill and circulatory flow arrest in surgical treatment of intracranial aneurysms: a historical review. Neurosurg Focus 2014;36:E10.

8. Groff MW, Adams DC, Kahn RA, et al. Adenosine-induced transient asystole for management of a basilar artery aneurysm. Case report. $J$ Neurosurg 1999;91:687-90.

9. Zäll S, Edén E, Winsö I, et al. Controlled hypotension with adenosine or sodium nitroprusside during cerebral aneurysm surgery: effects on renal hemodynamics, excretory function, and renin release. Anesth Analg 1990;71:631-6.

10. Hashimoto T, Young WL, Aagaard BD, et al. Adenosine-induced ventricular asystole to induce transient profound systemic hypotension in patients undergoing endovascular therapy. Doseresponse characteristics. Anesthesiology 2000;93:998-1001.

11. Powers CJ, Wright DR, McDonagh DL, et al. Transient adenosineinduced asystole during the surgical treatment of anterior circulation cerebral aneurysms: technical note. Neurosurgery 2010;67(2 Suppl Operative):ons461-ons470.

12. Makaryus JN, Catanzaro JN, Friedman ML, et al. Persistent seconddegree atrioventricular block following adenosine infusion for nuclear stress testing. J Cardiovasc Med 2008;9:304-7.

13. Lerman BB, Belardinelli L. Cardiac electrophysiology of adenosine. Basic and clinical concepts. Circulation 1991;83:1499-509.
14. Owall A, Gordon E, Lagerkranser M, et al. Clinical experience with adenosine for controlled hypotension during cerebral aneurysm surgery. Anesth Analg 1987;66:272-234.

15. Khan SA, Nimjee SM, Guinn NN, et al. The use of Adenosine in Cerebral Aneurysm Clipping: a Review. Curr Anesthesiol Rep 2013;3:210-3.

16. Lee SH, Kwun BD, Kim JU, et al. Adenosine-induced transient asystole during intracranial aneurysm surgery: indications, dosing, efficacy, and risks. Acta Neurochir 2015;157:1879-86.

17. Bendok BR, Gupta DK, Rahme RJ, et al. Adenosine for temporary flow arrest during intracranial aneurysm surgery: a single-center retrospective review. Neurosurgery 2011;69:815-21.

18. Andrade-Barazarte $\mathrm{H}$, Luostarinen $\mathrm{T}$, Goehre F, et al. Transient cardiac arrest induced by adenosine: a tool for contralateral clipping of internal carotid artery-ophthalmic segment aneurysms. World Neurosurg 2015;84:1933-40.

19. Nimjee SM, McDonagh DL, Agrawal A, et al. A case of high-dose adenosine usage for anterior communicating artery aneurysm clip ligation: what is the dose limit for a resistant response? Asian $J$ Neurosurg 2017. epub.

20. Luostarinen T, Takala RS, Niemi TT, et al. Adenosine-induced cardiac arrest during intraoperative cerebral aneurysm rupture. World Neurosurg 2010;73:79-83.

21. Vealey R, Koht A, Bendok BR. Multidose adenosine used to facilitate microsurgical clipping of a cerebral aneurysm complicated by intraoperative rupture: a case report. A A Case Rep 2017;8:109-12.

22. Heppner PA, Ellegala DB, Robertson N, et al. Basilar tip aneurysm - adenosine induced asystole for the treatment of a basilar tip aneurysm following failure of temporary clipping. Acta Neurochir 2007;149:517-21.

23. Britz GW, Asystole A-IT. Methodist DeBakey Cardiovasc J 2014;10:220-3.

24. Nussbaum ES, Sebring LA, Ostanny I, et al. Transient cardiac standstill induced by adenosine in the management of intraoperative aneurysmal rupture: technical case report. Neurosurgery 2000;47:240-3.

25. Deb K, Ghosh J, Jain H, et al. Adenosine in difficult aneurysm surgeries: report of two cases. J Neuroanaesth Crit Care 2014;1:66-8.

26. Cerqueira MD, Verani MS, Schwaiger M, et al. Safety profile of adenosine stress perfusion imaging: results from the Adenoscan Multicenter Trial Registry. J Am Coll Cardiol 1994;23:384-9.

27. Owall A, Järnberg PO, Brodin LA, et al. Effects of adenosine-induced hypotension on myocardial hemodynamics and metabolism in fentanyl anesthetized patients with peripheral vascular disease. Anesthesiology 1988;68:416-21.

28. Kahn RA, Moskowitz DM, Marin ML, et al. Safety and efficacy of high-dose adenosine-induced asystole during endovascular AAA repair. J Endovasc Ther 2000;7:292-6.

29. Bebawy JF, Zeeni C, Sharma S, et al. Adenosine-induced flow arrest to facilitate intracranial aneurysm clip ligation does not worsen neurologic outcome. Anesth Analg 2013;117:1205-10. 